\title{
Alternative expression of TCR related genes in patients with chronic myeloid leukemia
}

\author{
Xianfeng Zha ${ }^{1 \dagger}$, Xiaojuan Yan ${ }^{1 \dagger}$, Qi Shen ${ }^{1}$, Yuping Zhang ${ }^{2}$, Xiuli Wu', Shaohua Chen ${ }^{1}$, Bo Li ${ }^{1}$, Lijian Yang $^{1}$, \\ Suxia Geng ${ }^{3}$, Jianyu Weng ${ }^{3}$, Xin Du ${ }^{3}$ and Yangqiu Li ${ }^{1,4^{*}}$
}

\begin{abstract}
A previous study has demonstrated a significant decrease in the TCR gene expression level in chronic myeloid

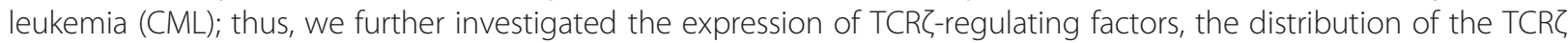
3' untranslated region (3'-UTR) splice variants, and the expression level and correlation of the alternative splicing factor/splicing factor 2 (ASF/SF-2), FCERly and ZAP-70 genes. TCRZ 3'-UTR splice variants were identified in peripheral blood mononuclear cells (PBMCs) from 14 healthy individuals, 40 patients with CML and 22 patients with CML in complete remission (CML-CR) by RT-PCR. The expression level of the TCRZ, FCERly, ASF/SF-2 and ZAP-70 genes was analyzed by real-time quantitative PCR. While the expression of TCR gene in the CML group was significantly lower than that in the healthy individual and CML-CR groups, a significantly higher expression of the FceRly and ASF/SF-2 genes was found in the CML group. Two types of splicing forms were detected in all of the healthy individual CML-CR cases: wild type (WT) TCR 3'-UTR and alternatively splieced (AS) TCR 3'-UTR which have been alternatively

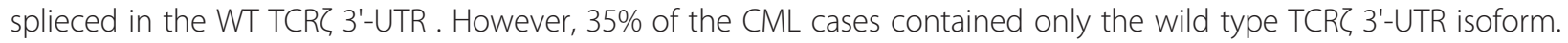
Based on the TCR $3^{\prime}$-UTR isoform expression characteristic, we divided the patients with CML into two subgroups:

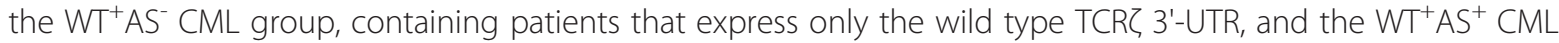
group, which contained patients that expressed two TCR 3'-UTR isoforms. A significantly different ASF/SF-2 and FceRly gene expression pattern was found between the $\mathrm{WT}^{+} A S^{-}$and $W T^{+} A S^{+} C M L$ groups. We concluded that defective TCR expression may be characterized in the $\mathrm{WT}^{+} A S^{-}$and $\mathrm{WT}^{+} A S^{+} C M L$ subgroups by the different gene expression pattern. The overexpression of ASF/SF2, which alternatively splices the TCR $3^{\prime}$-UTR, is thought to participate in feedback regulation. The characteristics of TCR 3 '-UTR alternative splicing may be a novel immunological marker for the evaluation of the CML immune status.
\end{abstract}

Keywords: ASF/SF-2gene, TCR $33^{\prime}-U T R$, TCR gene, FCERly gene, Chronic myeloid leukemia, Real-time PCR

\section{Introduction}

Chronic myeloid leukemia (CML) is a clonal hematopoietic stem cell disease that is characterized by the Philadelphia chromosome $(\mathrm{Ph})$, which is generated by the reciprocal translocation $\mathrm{t}(9 ; 22)(\mathrm{q} 34 ; \mathrm{q} 11)$ that results in the fusion of the $\mathrm{c}$-abl oncogene 1 (ABL1) with the breakpoint cluster region (BCR) gene [1]. T cell immunodeficiency including thymic output function, abnormal $\mathrm{T}$ cell receptor (TCR) repertoire expression and, in part, abnormal TCR signal

\footnotetext{
* Correspondence: yangqiuli@hotmail.com

${ }^{\dagger}$ Equal contributors

'Institute of Hematology, Medical College, Jinan University, Guangzhou 510632, China

${ }^{4}$ Key Laboratory for Regenerative Medicine of Ministry of Education, Jinan University, Guangzhou 510632, China

Full list of author information is available at the end of the article
}

transduction, such as that involving the TCR $\zeta$ chain is found in patients with CML [2-6], and $\mathrm{T}$ cell function becomes suppressed as the disease progresses in some patients.

The TCR/CD3 complex plays a central role in $\mathrm{T}$ cell activation. This complex comprises of two chains, $\alpha \beta$ or $\gamma \delta$, these chains are noncovalently associated with CD3 subunits, which include four transmembrane proteins: $\mathrm{CD} 3 \gamma, \mathrm{CD} 3 \delta, \mathrm{CD} 3 \varepsilon$ and $\mathrm{CD} 3 \zeta$ (also referred to as TCR $)$ ). These subunits are known to form three distinct dimers, $\mathrm{CD} 3 \gamma \varepsilon, \mathrm{CD} 3 \delta \varepsilon$, and CD3 $\zeta$, to mediate TCR signal transduction [7-10]. There are four tyrosine kinase families involved in TCR signal transduction including the Csk, Src, Tec, and ZAP-70 (CD3 zeta chain associated protein kinase $70 \mathrm{kDa}$ ) kinase families [11]. ZAP-70 is a cytosolic 
protein that is recruited to the $\mathrm{T}$ cell plasma membrane following TCR stimulation and binds to phosphorylated TCR $\zeta$ immunoreceptor tyrosine-based activation motifs (ITAMs); it plays a critical role in activating downstream T cell signal transduction pathways following TCR engagement [11]. There is evidence that the Fce receptor type Iy (FceRI $\gamma$ ) chain, which is a member of the TCR $\zeta$ chain protein family and a component of the high-affinity IgE receptor, can replace a functionally deficient TCR $\zeta$ chain and facilitate TCR/CD3 complex-mediated signaling [12,13].

The absence of the TCR $\zeta$ chain not only influences the TCR expression on the cell membrane and the number of single positive (i.e., CD4+ or CD8+) circulating T cells, it also impairs the proliferative response and the mature $\mathrm{T}$ cell activation level. T cells from patients with leukemia are functionally impaired, and this is related to decrease TCR $\zeta$ chain expression $[2,3,5,14]$. Recently, we has reported the expression pattern of the four CD3 genes in patients with AML and CML $[2,4,5,15]$, and it has been reported that the aberrant $\mathrm{TCR} \zeta$ chain expression found in the T cells of patients with systemic lupus erythematosus (SLE) may be associated with the decreased stability and translation of a TCR $\zeta$ mRNA with an alternatively spliced 3'-untranslated region [16]. However, the mechanism of TCR $\zeta$ deficiency in T cells in patients with cancer remains unclear.

The TCR $\zeta$ gene spans $31 \mathrm{~kb}$ in the chromosome 1q23.1 locus and has eight exons that are separated by introns ranging from $700 \mathrm{bp}$ to greater than $8 \mathrm{~kb}$ $[17,18]$. The TCR $\zeta$ mRNA is a $1,472 \mathrm{~kb}$ spliced product of the eight exons with a 492 bp coding region and a long downstream 906 bp 3'-untranslated region (UTR), which is encoded by exon VIII [19]. The stability of the TCR $\zeta$ mRNA is mainly influenced by the downstream 3' untranslated region and poly A tail. The $906 \mathrm{bp}$ TCR $\zeta$ 3'-UTR has several polyadenylation sites. Exon VIII comprises 20 amino acids of the carboxy-terminus and the 3'-UTR of TCR $\zeta$ chain. Recently, it has been reported that there are several TCR $\zeta$ chain isoforms with different 3'-UTR nucleotide sequences in mouse T cells [20]. The activation of alternative splicing within the 3'-UTR through two internal (5' and $3^{\prime}$ ) splice sites results in a splice deletion of 562 bases (nucleotides 672-1233), leading to the generation of a 344 bp alternatively spliced (AS) variant [21]. The 344 bp AS TCR $\zeta$ isoform lacks two critical regulatory adenosine/uridinerich elements (ARE) and a translation regulatory sequence. The stability and translation of this isoform are significantly lower than that of the 906 bp WT TCR isoform; consequently, the relative amount of TCR $\zeta$ protein generated by the AS isoform is significantly lower than that from the WT isoform [22,23].

$\mathrm{T}$ cells from healthy individuals predominantly express the wild type (WT) isoform, whereas an increased level of the AS isoform was reported in T cells from SLE patients [23]. Frequent mutations/polymorphisms and aberrant splicing of the downstream 3'-UTR may affect the stability and/or transport of the TCR $\zeta$ chain mRNA, leading to its downregulation in SLE T cells [23]. Although differential expression of the TCR $\zeta 3$ '-UTR isoforms contributes to differential TCR $\zeta$ protein expression levels, the factor(s) regulating the alternative splicing of the TCR $\zeta 3$ '-UTR is unknown [19].

Alternative splicing is a powerful gene regulation mechanism that results in the generation of numerous transcripts and proteins from a single gene [24]. Splice site selection is regulated by cis-acting elements such as intronic and exonic splicing enhancer and silencer sequences, respectively $[25,26]$. Alternative splicing factor/splicing factor 2 (ASF/SF2) is a prototypical SR protein that was originally identified in HeLa nuclear extract as a factor required to reconstitute splicing in S100 cellular extract $[27,28]$ and influence alternative splicing site selection in a concentration-dependent manner $[28,29]$. ASF/SF2 acts early during spliceosome assembly and participates in multiple steps during constitutive splicing and the regulation of alternative splicing by interacting with the pre-mRNAs and/or other splicing factors $[28,30,31]$. ASF/SF2 regulates the alternative splicing of eukaryotic genes such as caspase-9 and the $\mathrm{T}$ cell differentiation marker CD45 [19,32,33]. Recently, the involvement of ASF/SF2 in the posttranscriptional regulation of TCR $\zeta$ was described in $\mathrm{T}$ cells from patients with SLE. ASF/SF2 binds to the 3'UTR of TCR $\zeta$ and regulates the shift in alternative splicing from the AS to the WT isoform and regulates TCR $\zeta$ protein expression [19].

Based on our previous finding that the TCR $\zeta$ chain gene expression level was significantly decreased in $\mathrm{CML}$, we further investigated the expression pattern of the TCR $\zeta$ regulating factors TCR $\zeta 3$ '-UTR and ASF/SF-2, as well as the expression level and correlation of FceRI $\gamma$ and ZAP-70, to evaluate the ASF/SF-2 regulating effects of TCR $\zeta$ 3'-UTR formation.

\section{Materials and methods \\ Samples}

Forty newly diagnosed, untreated chronic phase CML patients, including 27 males and 13 females (13-71 years old; median age: 44 years), and 22 patients with CML complete remission ( 16 cases after allo-HSCT and 6 cases after imatinib therapy) were included in this study [6]. The BCR-ABL fusion gene was detected in all samples by RT-PCR. Fourteen healthy individuals including 8 males and 6 females (23-53 years old; median age: 28.5 years) served as controls. Peripheral blood mononuclear cells (PBMCs) were isolated from heparinized venous blood by Ficoll-Paque gradient centrifugation. 
All procedures were conducted according to the guidelines of the Medical Ethics Committee of the Health Bureau of the Guangdong Province in China.

\section{RT-PCR for TCR乙 3'-UTR amplification}

Total RNA was isolated from the PBMC samples using the Trizol reagent according to the manufacturer's protocol (Invitrogen, Carlsbad, CA, USA). First-strand cDNA was synthesized using the random hexamers and reverse transcriptase in the Superscript II Kit (PowerScript Reverse, BD, San Jose, CA, USA) according to the manufacturer's instructions. The primers for amplification of the TCR $\zeta$ 3'-UTR and the $\beta 2$-microglobulin $(\beta 2 \mathrm{M})$ gene, which was used as a control, are listed in Table 1. RT-PCR amplification of the TCR $\zeta$ 3'-UTR was performed as previously described by Nambiar et al. [23].

\section{Real-time quantitative reverse transcription-polymerase chain reaction ( $q R T-P C R$ )}

The expression level of the TCR $\zeta$, FceRI $\gamma$, ASF/SF-2, ZAP-70, and $\beta 2$-microglobulin $(\beta 2 \mathrm{M})$ genes was determined by SYBR Green I real-time PCR. Briefly, PCR was performed in a $20 \mu \mathrm{L}$ total volume that contained $1 \mu \mathrm{L}$ of cDNA, $9 \mu \mathrm{L}$ of $2.5 \times$ SYBR Green I mix (Tiangen, Beijing, China), and $10 \mu \mathrm{mol} / \mathrm{L}$ primer pairs. After an initial denaturation at $95^{\circ} \mathrm{C}$ for $3 \mathrm{~min}, 45$ cycles consisting of the following procedure was performed using an MJ Research DNA Engine Opticon 2 PCR cycler (BIO-RAD, USA): $10 \mathrm{~s}$ at $95^{\circ} \mathrm{C}, 30 \mathrm{~s}$ at $64^{\circ} \mathrm{C}$ for $\beta 2 \mathrm{M}$ and ASF/SF-2, $60^{\circ} \mathrm{C}$ for TCR $\zeta$ and ZAP-70, and $40 \mathrm{~s}$ at $60^{\circ} \mathrm{C}$ for FceRIy. The relative amount of the genes of interest and the $\beta 2 \mathrm{M}$ reference gene was measured in two independent assays. The data are presented as the relative expression of the genes of interest relative to the internal control gene as determined by the $2^{(-\Delta \Delta C T)}$ method $[2,34]$. Additionally, the specific amplification of the PCR products was analyzed by melting curve analysis and agarose gel electrophoresis. The real-time PCR primers used for all of the gene amplifications were synthesized by Shanghai Biological Engineering Technology Services Co., Ltd. (Table 1).

\section{Statistical analysis}

Univariate analyses were performed using the MannWhitney test to compare the means of the differences in the mRNA expression between the CML and healthy control groups. Pearson correlation and linear regression analyses were used to estimate the correlation between age and the mRNA level of the different genes in the different samples using the SPSS 11.5 statistical software. A difference with a $P<0.05$ was considered statistically significant.

\section{Results}

TCR $33^{\prime}$-UTR isoforms in CML

It has been reported that two types of spliceosomes could be found on the TCR $\zeta 3$ '-UTR $[19,23]$. In this study, the alternatively-spliced TCR $\zeta$ 3'-UTR (344 bp) and the wild type TCR $\zeta$ 3'-UTR (906 bp) could be detected in the same PCR reaction for all healthy individual and CML complete remission (CML-CR) samples (Figure 1). Both PCR products were cloned and sequenced, and the sequence was confirmed by comparison with the sequence found in the NCBI GenBank (data not shown). Both TCR 3 3'-UTR isoforms were also identified in all CML-CR patient samples; however, 35\% of the CML cases (14 cases) contained only the wild type TCR $\zeta$ 3'-UTR (906 bp), and this was significantly different from the healthy individual and CML-CR groups $(p<0.001, p<0.001)$.

\section{Characteristic expression of ASF/SF-2 in CML}

The ASF/SF-2 expression level was quantified by realtime PCR [35]. Although there was only one peak at $83.5^{\circ} \mathrm{C}$ in the melting curve analysis (Figure 2), two PCR

Table 1 List of primers used for PCR analysis

\begin{tabular}{|c|c|c|c|}
\hline Primer & Sequence $\left(5^{\prime}-3^{\prime}\right)$ & Association number & Product size \\
\hline$\overline{T C R \zeta 3^{\prime}-U T R-f}$ & CAGCCAGGGGATTTCCACCACTCAAAG & NM_000734.3 & $906 \mathrm{bp} / 344 \mathrm{bp}$ \\
\hline TCRZ3'-UTR-r & CCCTAGTACATTGACGGGTITTCCTG & & \\
\hline ASF/SF-2-f & TCTCTGGACTGCCTCCAAGT & NM_006924.4 & $473 \mathrm{bp} / 273 \mathrm{bp}$ \\
\hline ASF/SF-2-r & GGCTTCTGCTACGACTACGG & & \\
\hline$T C R \zeta-f$ & GCCAGAACCAGCTCTATAAC & NM_009743.3 & $166 \mathrm{bp}$ \\
\hline TCRC-r & TAGGCCTCCGCC ATCTTATC & & \\
\hline FceRly-f & GAGCCTCAGCTCTGCTATATCC & NM_004106.1 & $172 \mathrm{bp}$ \\
\hline FceRly-r & TCTCGTAAGTCTCCTG GTGCC & & \\
\hline ZAP-70-f & GTTGACTCATCCTCAGAGACGAAT & NM_001079.3 & $183 \mathrm{bp}$ \\
\hline ZAP-70-r & AGGTTATCGCGCTTCAGGAA & & \\
\hline$\beta 2 M-f$ & TACACTGAATTCCACCCCCAC & $J 00105$ & $144 \mathrm{bp}$ \\
\hline$\beta 2 \mathrm{M}-\mathrm{r}$ & CACTCAATCCAAATGCGGCA & & \\
\hline
\end{tabular}






products of 473 and 273 bp were identified by agarose gel electrophoresis (Figure 2). Both of the PCR products were cloned and sequenced, and two specific ASF/SF-2 transcripts were identified by comparison of the sequences in the NCBI GenBank (Figure 3). The $273 \mathrm{bp}$ product was identified as ASF/SF-2 transcript 1, and the 473 bp product was identified as ASF/SF-2 transcript 2 [35]. Thus, the ASF/SF-2 expression level represented the total expression level of all of the ASF/SF-2 transcripts in this study.

\section{Expression pattern of the ASF/SF-2, TCRZ, ZAP-70 and FceRly genes in CML}

The expression level of the TCR $\zeta$, FceRI $\gamma$, ASF/SF-2, ZAP-70 genes was determined by real-time PCR using the SYBR Green I technique and quantitatively assessed by comparison with the $\beta 2 \mathrm{M}$ reference gene using cDNA from PBMCs collected from CML, CML-CR and healthy control samples. Each of the four genes could be detected in every sample. To establish proper real-time quantitative PCR reaction conditions, we used diluted Molt-4 cDNA to make relative standard curves. The results demonstrated that the high amplification efficiency of the four targeted genes was successful and consistent with that of the $\beta 2 \mathrm{M}$ reference gene. In addition, the specific amplification of the PCR products was confirmed by melting curve and agarose electrophoresis analysis. A single melting curve peak and the expected PCR products were confirmed, the PCR products of all of the genes were randomly selected and sent for sequencing, and the sequencing results were confirmed by BLAST analysis to compare with data in GenBank (data not shown).

The expression level of the TCR $\zeta$, FceRI $\gamma$, ASF/SF-2 and ZAP-70 genes in PBMCs from CML, CML-CR and

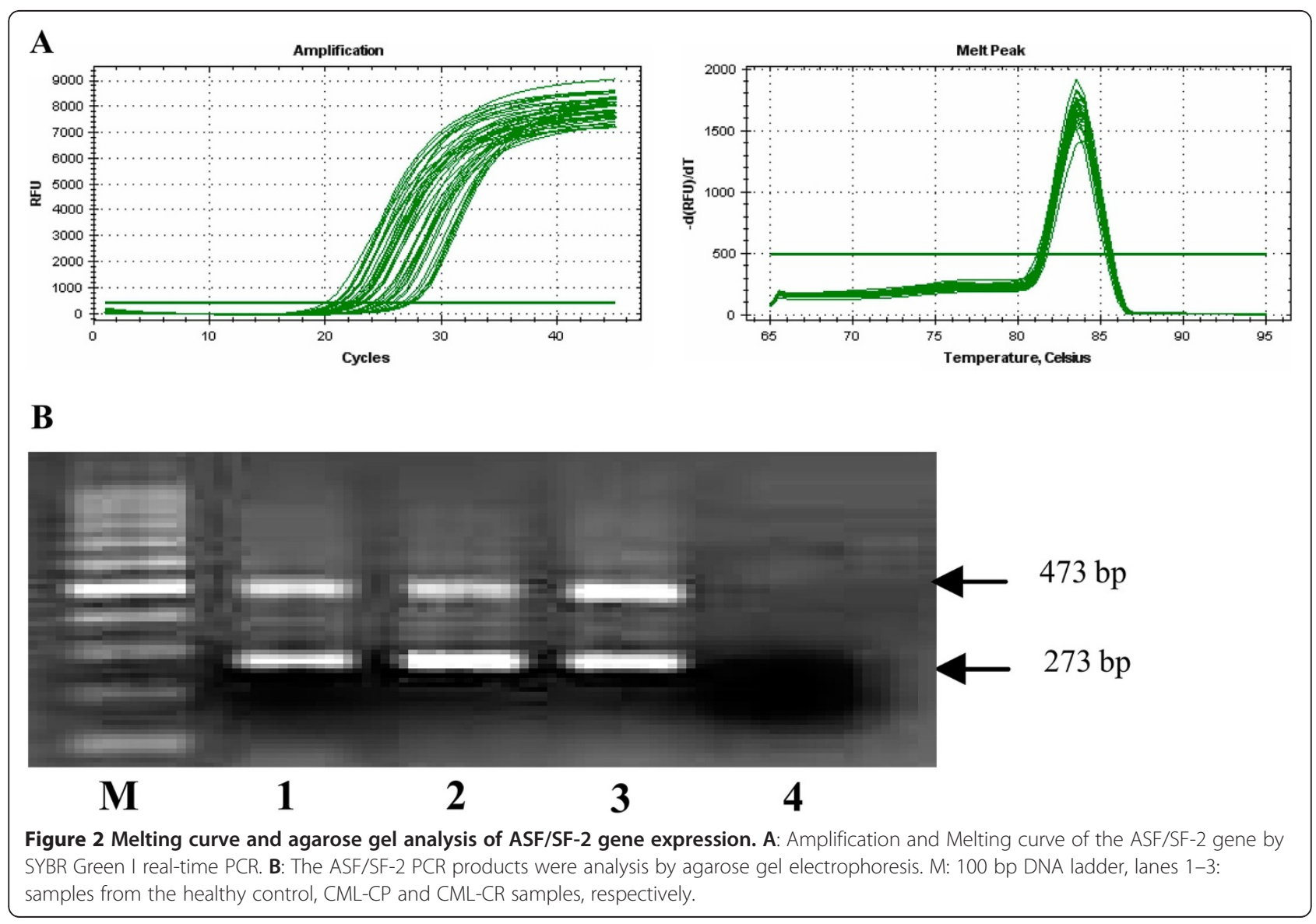




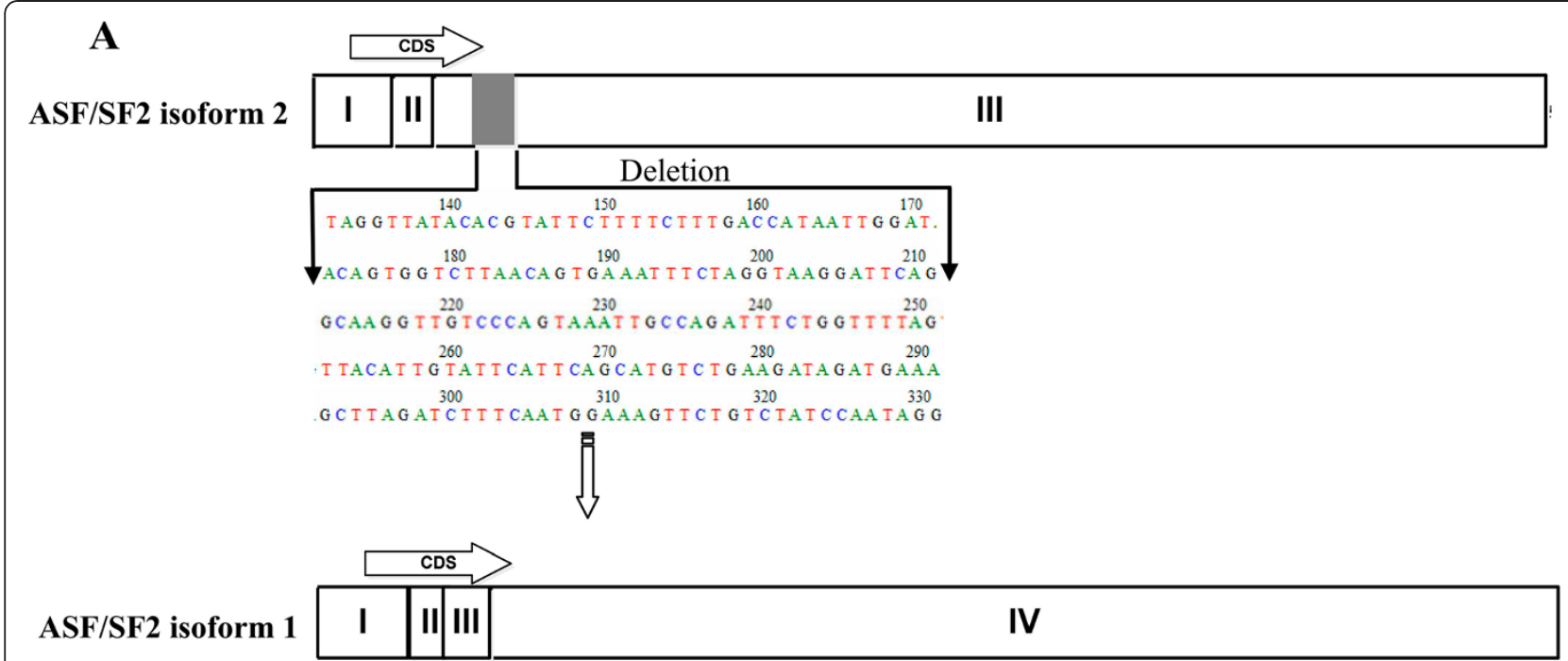

B

541 GCTATGGCCC CCCATCCAGG CGGTCTGAAA ACAGAGTGGT TGTCTCTGGA CTGCCTCCAA

601 GTGGAAGTTG GCAGGATTTA AAGGATCACA TGCGTGAAGC AGGTGATGTA TGTTATGCTG

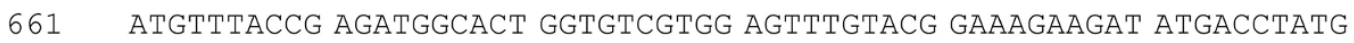

721 CAGTTCGAAA ACTGGATAAC ACTAAGTTTA GATCTCATGA GGTAGGTTAT ACACGTATTC

781 TTTTCTTTGA CCAGAATTGG ATACAGTGGT CTTAACAGTG GAATTTCAAG GTAAGGATTC

841 AGGCAAGGTT GTCCAAGTAA ATTGCCAGAT TTCTGGTTTT AGTTACATTG TATTCATTCA

901 GCATGTCTGA AGATAGATGA AAGCTTAGAT CTTTCAATGG AAAGTTCTGT CTATCCAATA

961 GGGAGAAACT GCCTACATCC GGGTTAAAGT TGATGGGCCC AGAAGTCCAA GTTATGGAAG

1021 ATCTCGATCT CGAAGCCGTA GTCGTAGCAG AAGCCGTAGC AGAAGCAACA GCAGGAGTCG

1081 CAGTTACTCC CCAAGGAGAA GCAGAGGATC ACCACGCTAT TCTCCCCGTC ATAGCAGATC

Figure 3 A: A schematic view of ASF/SF-2 gene bearing the isoform 1 (bottom) and 2 (top). B: Sequence of the ASF/SF-2 transcript isoform 2 PCR product. The box indicates the 200 bp sequence that was cut in transcript isoform 2, and the gray indicates the PCR primer.

healthy controls is shown in Figure 4. The expression of the TCR $\zeta$ gene in the CML group was significantly lower than that in the healthy control and CML-CR groups $(p=0.027, p<0.001)$, while a significantly higher level of FceRI $(p=0.001, p<0.001)$ and ASF $/$ SF- $2(p=0.002$, $p<0.001)$ gene expression was found in the CML chronic phase (CML-CP) group.

The expression characteristics of the TCRZ, FcERly, ASF/SF-2 and ZAP-70 genes are related to TCRZ 3'-UTR spliceosome

To evaluate the effect of the alternatively spliced TCR $\zeta$ 3 '-UTR on the expression and regulation of the TCR $\zeta$ chain and its related genes according to TCR $\zeta 3$ '-UTR spliceosome characteristics, patients with CML were divided in two subgroups: patients who only expressed the wild type TCR $33^{\prime}-\mathrm{UTR}$ (the $\mathrm{WT}^{+} \mathrm{AS}^{-} \mathrm{CML}$ group), and patients who expressed both TCR $\zeta$ 3'-UTR forms (the $\mathrm{WT}^{+} \mathrm{AS}^{+} \mathrm{CML}$ group). When the expression level of the TCR $\zeta$, FceRIy, ASF/SF-2 and ZAP-70 genes was compared between both groups, a significantly higher level of ASF/SF-2 and FceRIY gene expression was found in the $\mathrm{WT}^{+} \mathrm{AS}^{-} \mathrm{CML}$ group $(p=0.014, p=0.005)$, and the level of TCR $\zeta$ and ZAP-70 gene expression was approximately two-fold higher in the $\mathrm{WT}^{+} \mathrm{AS}^{-} \mathrm{CML}$ group; however, there was no significant difference in the expression of thses genes when compared with the $\mathrm{WT}^{+} \mathrm{AS}^{+} \mathrm{CML}$ group ( $p=0.319, p=0.261$ ) (Figure 5).

The ASF/SF-2, TCRZ, ZAP-70 and FcERly gene expression is correlated in $\mathrm{CML}$

ASF/SF-2 regulates TCR $\zeta$ expression by binding to the TCR $\zeta$ 3'-UTR and down-regulating the alternativelyspliced TCR $\zeta$ 3'-UTR isoform. To further investigate the mechanism for lower TCR $\zeta$ expression in CML, we analyzed correlations between the relative ASF/SF-2, TCR $\zeta$, ZAP-70 and FceRIy gene expression levels. A negativecorrelation was observed between the expression level of TCR $\zeta$ and ASF/SF-2 expression, but the difference was 

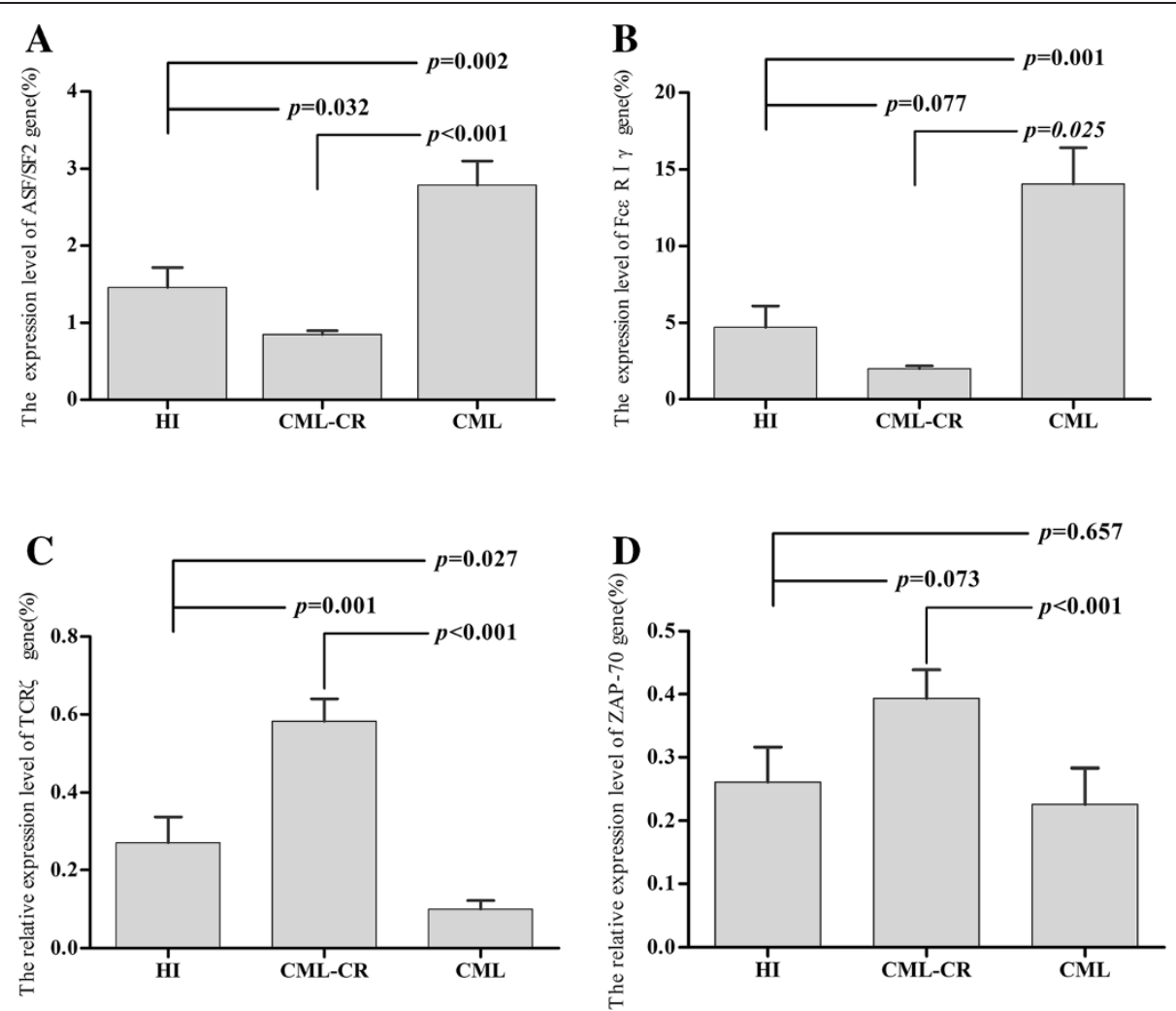

Figure 4 The expression level of the ASF/SF-2, TCR , ZAP-70and FcERly genes in the CML, CML-CR and healthy control groups (HI). A: ASF/SF-2; B: FCERlY; C: TCRZ; and D: ZAP-70.
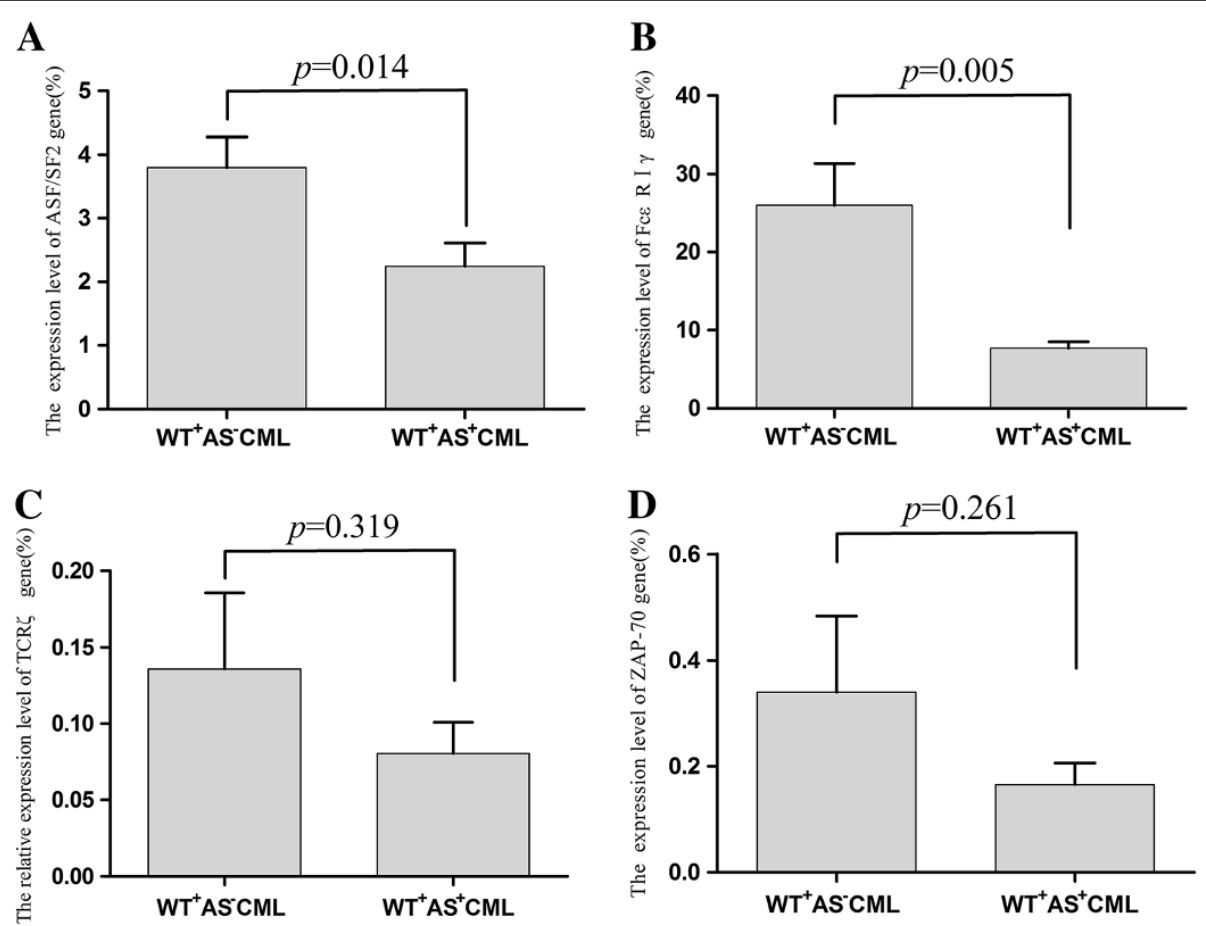

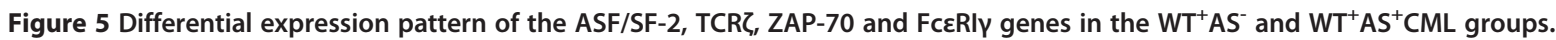
A: ASF/SF-2; B: FCERly; C: TCRZ; and D: ZAP-70. 
not statistically significant $(\mathrm{r}=-0.314, p=0.275)$. In contrast, the negative correlation between these genes was lost in the CML-CR and CML groups $(\mathrm{r}=0.001, p=0.997$; $\mathrm{r}=0.076, p=0.642$, respectively). When we further analyzed the correlation of the TCR $\zeta$ and ASF/SF-2 gene expression in the $\mathrm{WT}^{+} \mathrm{AS}^{-}$and $\mathrm{WT}^{+} \mathrm{AS}^{+} \mathrm{CML}$ groups, we found that a similar negative-correlation could be observed in the $\mathrm{WT}^{+} \mathrm{AS}^{+} \mathrm{CML}$ group $(\mathrm{r}=-0.17, p=0.407)$, and no correlation was observed in the $\mathrm{WT}^{+} \mathrm{AS}^{-} \mathrm{CML}$ group ( $\mathrm{r}=0.198, p=0.497$ ) (Figure 6).

Similar to a previous finding [36], a negative correlation between the level of TCR $\zeta$ and FceRIy gene expression was found in the healthy group, though the difference was not statistically significant $(r=-0.218$, $p=0.454)$, and this negative correlation was lost in the CML group $(\mathrm{r}=0.076, \quad p=0.642)$; however, the negative-correlation remained in the $\mathrm{WT}^{+} \mathrm{AS}^{+} \mathrm{CML}$ group $(\mathrm{r}=-0.066, p=0.748)$, and no correlation was observed between these genes in the $\mathrm{WT}^{+} \mathrm{AS}^{-} \mathrm{CML}$ group ( $r=0.165, p=0.573)$. In contrast, a significant positive correlation of the expression of both genes was found in the CML-CR group ( $\mathrm{r}=0.473, p=0.026)$ (Figure 7 ).

The expression correlation of the TCR $\zeta$ and ZAP-70 genes was analyzed, and a significant positive correlation was found in the healthy control, CML-CR and CML groups $(\mathrm{r}=0.600, p=0.023 ; \mathrm{r}=0.637, p=0.001$; and $\mathrm{r}=0.460, p=0.003$, respectively). The same result was also found in the $\mathrm{WT}^{+} \mathrm{AS}^{+} \mathrm{CML}$ group $(\mathrm{r}=0.737$, $p<0.001$ ), while no significant correlation was found in the $\mathrm{WT}^{+} \mathrm{AS}^{-} \mathrm{CML}$ group $(\mathrm{r}=0.320, p=0.265$ ) (Figure 8).

A significant positive correlation of the ASF/SF-2 and FceRIy expression level was found in the healthy control and CML groups $(\mathrm{r}=0.822 p<0.001$ and $\mathrm{r}=0.334$, $p=0.035$, respectively).

\section{Discussion}

\section{Defects inTCR/CD3 signaling in CML}

The TCR/CD3 complex plays a central role in T cell activation, and the alteration of any subunits in the complex may change the $\mathrm{T}$ cell activation level [7-10]. An abnormal TCR repertoire, lower thymic output function and lower CD3 gene expression have been described in CML [2-6]. Alternative CD3 gene expression levels may directly represent a characteristic of lower $\mathrm{T}$ cell activation [2-4]. In this study, the TCR $\zeta$ expression level was detected in 40 patients with chronic phase CML and compared with CML in complete remission and healthy individuals. Similar to our previous study, we found that the TCR $\zeta$ gene expression level in the CML group was significantly lower than that in healthy controls [2], and we further demonstrated that the TCR $\zeta$ gene expression level may be increased in patients with CML who achieved complete remission. It is possible that the high number of CML cells in the blood may have influenced
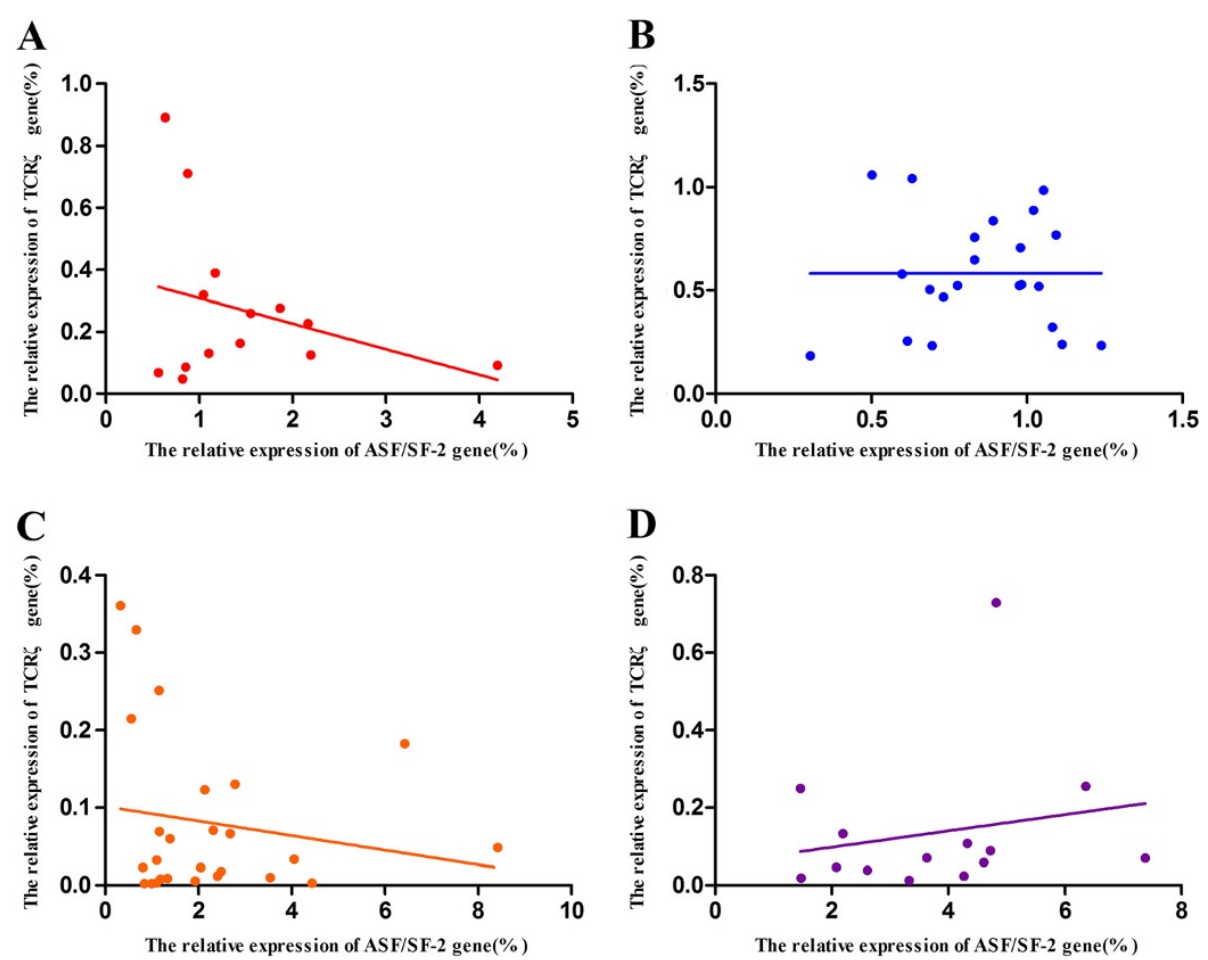

Figure 6 Correlation analysis of the TCR and ASF/SF-2 genes. A: Healthy controls; $\mathbf{B}: C M L-C R$ group; $\mathbf{C}: W^{+} A S^{+} C M L$ group; and $\mathbf{D}: W^{+} A S$ CML group. 

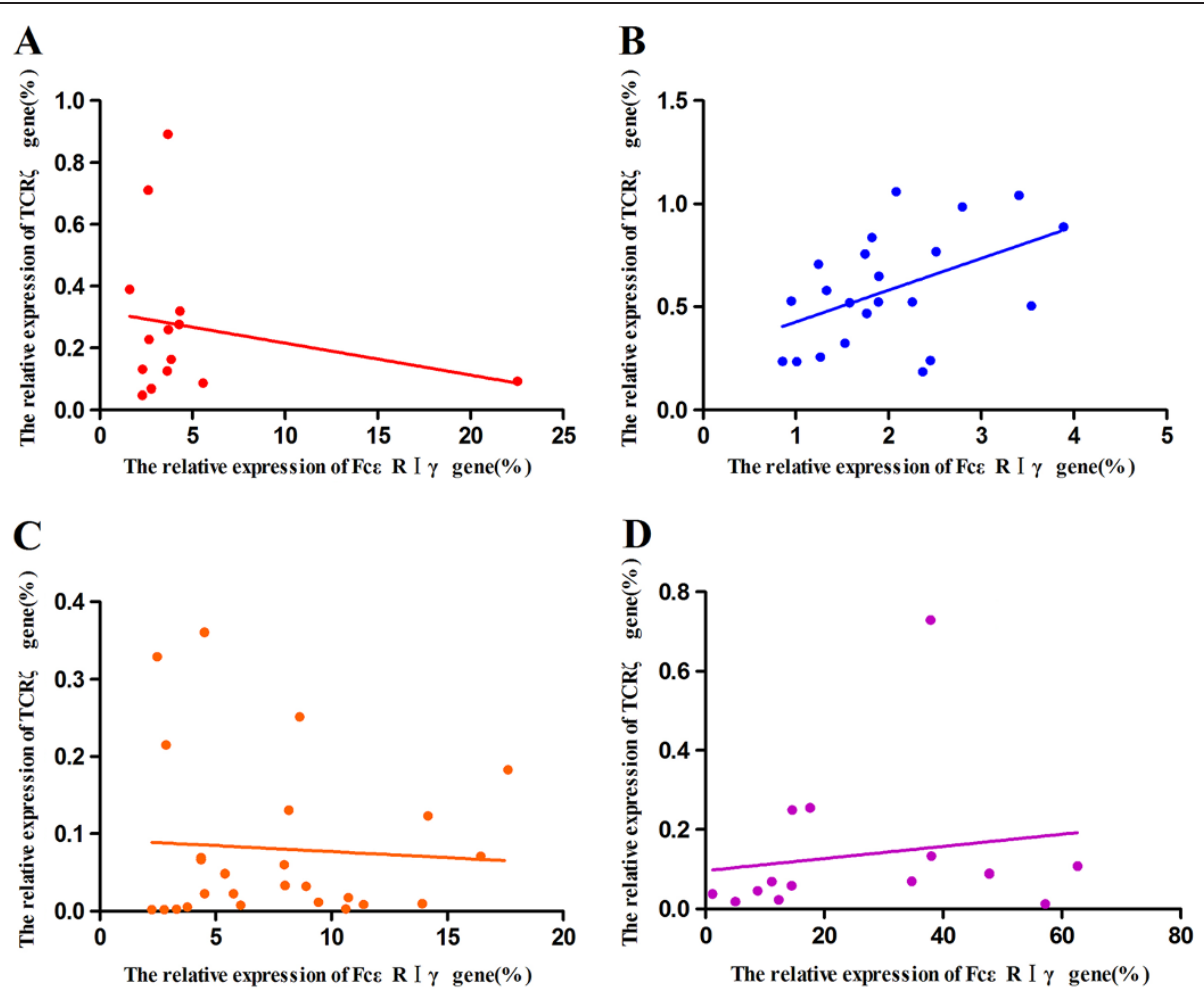


CML group.
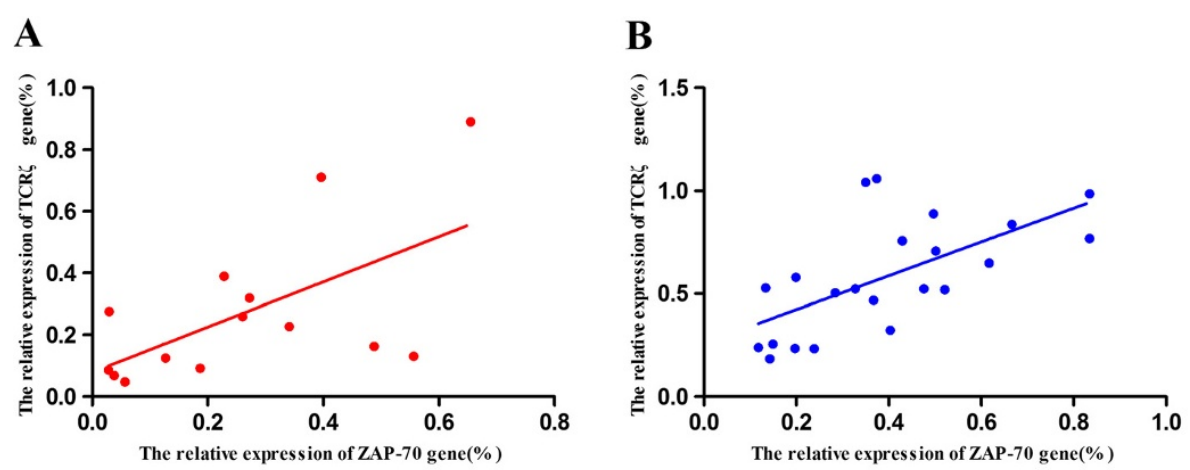

C

D
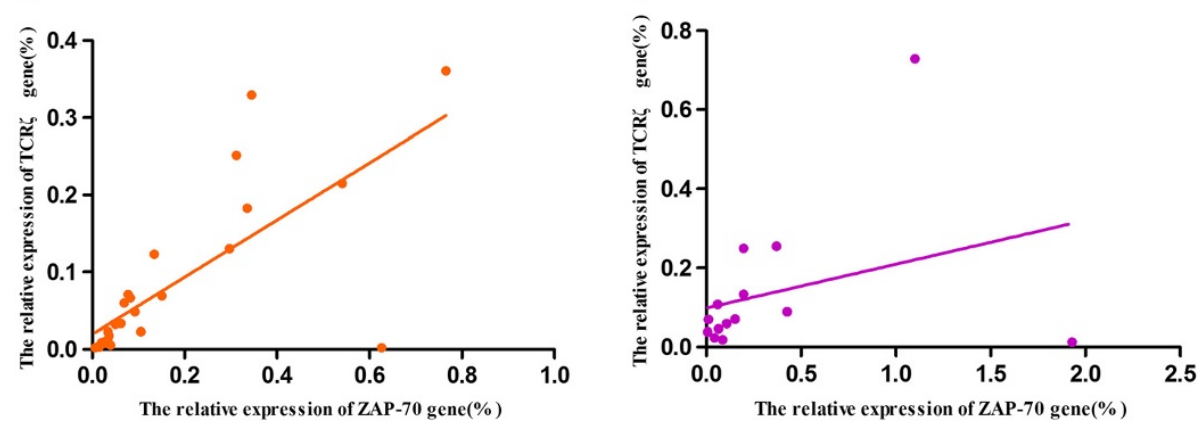

Figure 8 Correlation analysis of the TCR and ZAP-70 genes. A: Healthy controls; B: CML-CR group; $\mathbf{C}: W^{+} A S^{+} C M L$ group; and $\mathbf{D}: W T^{+} A S$ CML group. 
the results; however, our previous studies have demonstrated decreased expression of the gene and protein encoding the TCR $\zeta$ chain in purified $\mathrm{CD} 3+\mathrm{T}$ cells in chronic phase CML by quantitative real-time PCR and FCM, respectively [37]. Thus, we used PMBC samples as a simple method to analyze the expression characteristics of the TCR $\zeta$ chain and its related genes.

Unlike the TCR $\zeta$ chain, which mediates signaling through ZAP-70, FceRIY mediates signaling by associating with the phosphorylated protein kinase $S y k$, which is 100-fold more potent than ZAP-70 and is preferentially recruited to the FceRIY receptor [12,38-40]. Thus, FceRI $\gamma$ may substitute for deficiencies in the TCR $\zeta$ chain. In this study, we analyzed the FceRIy gene expression level and its correlation with TCR $\zeta$ gene expression in patients with CML. As expected, the FceRIy expression level was significantly increased in patients with CML, while its expression level was lower in patients who achieved complete remission. These data suggest that, in

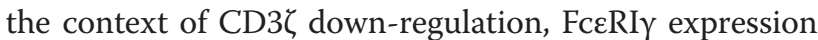
in CML is up-regulated to contribute to TCR signaling transduction in a manner similar to that of the conserved functional ITAM motif, which is a different immune status than that found in CLL, where the FceRIy expression level was not up-regulated and was not correlated with the TCR $\zeta$ expression level [36]. However, FceRIy expression level did not demonstrate negative correlation with TCR $\zeta$ expression level in patients with CML, suggesting that apparent defects in T cell-mediated immunity are involved in alternative immune regulation in CML. When we further analyzed the correlation in the $\mathrm{WT}^{+} \mathrm{AS}^{+}$and $\mathrm{WT}^{+} \mathrm{AS}^{-} \mathrm{CML}$ groups, we found that the negative-correlation remained in $\mathrm{WT}^{+} \mathrm{AS}^{+} \mathrm{CML}$ group, and by combining the gene expression characteristics of the $\mathrm{WT}^{+} \mathrm{AS}^{-} \mathrm{CML}$ group, it is thought that the defects in immune regulation is apparent in the $\mathrm{WT}^{+} \mathrm{AS}^{-} \mathrm{CML}$ group due to the differential distribution of TCR $\zeta-3$ UTR spliceosomes. An interesting and significant positive correlation between the expression of TCR $\zeta$ and FceRI $\gamma$ genes was found in the CML-CR group, and whether this is the result of an abnormal immune regulation status rather than immunodeficiency in patients with CML-CR remains an open question.

It is well known, ZAP-70 is a downstream factor that transduces TCR signals [41]. In this study, the finding of a significant positive correlation between the expression level of the TCR $\zeta$ and ZAP-70 genes in the healthy control, CML-CR and CML groups further supports the correlation of the TCR $\zeta$ and ZAP-70 genes in T cell activation.

\section{The molecular mechanism of decreased TCR in CML}

A lower transduction of the TCR signal may be a common feature in hematological malignancies [36]. The absence of the TCR $\zeta$ chain not only influences the TCR expression on the cell membrane and the number of single-positive (CD4+ or $\mathrm{CD} 8+$ ) circulating $\mathrm{T}$ cells, it also impairs the proliferative response and mature $\mathrm{T}$ cell activation level [42,43]. However, the mechanism of TCR $\zeta$ deficiency in T cells in patients with cancer is unclear. To gain insight into the molecular mechanism of TCR $\zeta$ deficiency in CML, we analyzed the distribution of the TCR 3 '-UTR isoforms, which contribute to the regulation of TCR $\zeta$ expression [19], and the ASF/SF-2 gene expression level, which regulates the alternative splicing of eukaryotic genes.

In general, the TCR $\zeta$ mRNA stability is mainly influenced by its downstream 3'-UTR. While the 906 bp WT 3'-UTR plays an important role in TCR $\zeta$ transcript stability, the 344 bp alternatively spliced 3'-UTRsignificantly influences the generation of the TCR $\zeta[22,23]$. Interestingly, while we found that $35 \%$ of the CML samples in this study contained only the wild type TCR $\zeta 3$ 'UTR isoform, the wild type and alternatively spliced TCR $\zeta 3^{\prime}$-UTRs isoform could be detected in all healthy individual and CML-CR samples. These results may account for the feedback regulation of the immune system in certain CML cases. Moreover, samples that contained only the wild type TCR $\zeta$ 3'-UTR isoform demonstrated a high expression level for the ASF/SF-2, FceRI $\gamma$, TCR $\zeta$ and ZAP-70 genes, and based on this finding, we tried to characterized the different CML subgroups using the different expression patterns of the TCR signaling components. A definitive characteristic was found when comparing the gene expression pattern of the ASF/SF-2, FceRI $\gamma$, TCR $\zeta$ and ZAP-70 genes in the $\mathrm{WT}^{+} \mathrm{AS}^{-}$and $\mathrm{WT}^{+} \mathrm{AS}^{+} \mathrm{CML}$ groups.

The involvement of ASF/SF2 in the post-transcriptional regulation of TCR $\zeta$ was described in T cells from patients with SLE. ASF/SF2 binds to the 3'-UTR of the TCR $\zeta$ mRNA and regulates a shift in alternative splicing from the AS to the WT isoform, which modulates TCR $\zeta$ protein expression [19]. Therefore, a higher ASF/SF2 expression level is correlated with a higher WT TCR $3^{\prime}$-UTR expression level, which results in a higher TCR $\zeta$ protein expression level. In this study, a significantly higher ASF/SF2 expression level was found in patients with CML who had a lower TCR $\zeta$ level, prompting the question of whether there is feedback regulation in patients with CML similar to that for the enhanced FceRIy expression level. However, this feedback regulation was unable to recover the TCR $\zeta$ expression level. Interestingly, significantly higher ASF/ SF2 expression was found in the $\mathrm{WT}^{+} \mathrm{AS}^{-}$group as compared with the $\mathrm{WT}^{+} \mathrm{AS}^{+} \mathrm{CML}$ group, a result that is in agreement with the biological findings. No study has reported similar results; thus, further investigation of more samples with outcome follow up for patients with CML is required in future studies. 
In conclusion, to our knowledge, this is the first study attempting to provide a global gene expression profile of the TCR $\zeta$ related genes: FceRIy, ASF/SF-2 and ZAP-70, and the distribution characteristics of the TCR 3 3'-UTR isoforms in de novo CML and CML-CR patients with TCR $\zeta$ defective. The preliminary data may indicate that defective TCR $\zeta$ expression may be characterized in the $\mathrm{WT}^{+} \mathrm{AS}^{-}$and $\mathrm{WT}^{+} \mathrm{AS}^{+} \mathrm{CML}$ subgroups with different gene expression patterns. The TCR $\zeta$ '-UTR alternative splicing characteristics may be a novel immunological marker for the evaluation of the CML immune status. Moreover, ASF/SF-2 may also be a target for regulation by the immune system to overcome immunodeficiency in CML.

\section{Competing interests}

Authors have no potential competing interest.

\section{Authors' contributions}

YQL contributed to concept development and study design. XFZ, XJY, QS, $X L W, S H C, B L$ and LJY performed the laboratory studies. YPZ, SXG, JYW and XD were responsible for collection of clinical data. YQL, XFZ and XJY coordinated the study and helped drafting the manuscript. All authors read and approved the final manuscript.

\section{Acknowledgments}

The study was supported by grants from the National Natural Science Foundation of China (No. 81100353, 81270604), the Natural Science Foundation of Guangdong Province, China (No. 9251063201000001), the Fundamental Research Funds for the Central Universities (No. 21611447, 21612116) and the Medical Science Foundation of Guangdong Province (A2011325).

\section{Author details}

${ }^{1}$ Institute of Hematology, Medical College, Jinan University, Guangzhou 510632, China. ${ }^{2}$ Department of Hematology, Guangzhou First Municipal People's Hospital Affiliated to Guangzhou Medical College, Guangzhou 510180, People's Republic of China. ${ }^{3}$ Department of Hematology, Guangdong General Hospital (Guangdong Academy of Medical Sciences), Guangzhou 510080, China. ${ }^{4}$ Key Laboratory for Regenerative Medicine of Ministry of Education, Jinan University, Guangzhou 510632, China.

Received: 25 September 2012 Accepted: 4 December 2012 Published: 10 December 2012

\section{References}

1. Smahel M: Antigens in chronic myeloid leukemia: implications for vaccine development. Cancer Immunol Immun 2011, 60:1665-1668.

2. Chen S, Yang L, Chen S, Li Y: TCR zeta chain expression in T cells from patients with CML. Hematology 2009, 14:95-100.

3. Chen X, Woiciechowsky A, Raffegerst S, Schendel D, Kolb HJ, Roskrow M: Impaired expression of the CD3-zeta chain in peripheral blood T cells of patients with chronic myeloid leukaemia results in an increased susceptibility to apoptosis. Br J Haematol 2000, 111:817-825.

4. Li Y: Alterations in the expression pattern of TCR zeta chain in T cells from patients with hematological diseases. Hematology 2008, 13:267-275.

5. Li Y, Geng S, Du X, Chen S, Yang L, Wu X, Li B, Schmidt CA, Przybylski GK: Restricted TRBV repertoire in CD4+ and CD8+ T-cell subsets from CML patients. Hematology 2011, 16:43-49.

6. Li Y, Geng S, Yin Q, Chen S, Yang L, Wu X, Li B, Du X, Schmidt CA, Przybylski GK: Decreased level of recent thymic emigrants in CD4+ and CD8 + T cells from CML patients. J Trans/ Med 2010, 8:47.

7. Call ME, Wucherpfennig KW: The T cell receptor: critical role of the membrane environment in receptor assembly and function. Annu Rev Immunol 2005, 23:101-125.
8. Call ME, Pyrdol J, Wucherpfennig KW: Stoichiometry of the T-cell receptorCD3 complex and key intermediates assembled in the endoplasmic reticulum. EMBO J 2004, 23:2348-2357.

9. Clevers $\mathrm{H}$, Alarcon B, Wileman T, Terhorst C: The T cell receptor/CD3 complex: a dynamic protein ensemble. Annu Rev Immuno/ 1988, 6:629-662.

10. Fischer A, de Saint Basile G, Le Deist F: CD3 deficiencies. Curr Opin Allergy Clin Immunol 2005, 5:491-495.

11. Fischer A, Pieard C, Chemin K: ZAP70: a master regulator of adaptive immunity. Semin Immunopathol 2010, 32:107-116.

12. Enyedy EJ, Nambiar MP, Liossis SN, Dennis G, Kammer GM, Tsokos GC: Fc epsilon receptor type I gamma chain replaces the deficient $T$ cell receptor zeta chain in $T$ cells of patients with systemic lupus erythematosus. Arthritis Rheum 2001, 44:1114-1121.

13. Koyasu S, D'Adamio L, Arulanandam AR, Abraham S, Clayton LK, Reinherz EL: $T$ cell receptor complexes containing Fc epsilon RI gamma homodimers in lieu of CD3 zeta and CD3 eta components: a novel isoform expressed on large granular lymphocytes. J Exp Med 1992, 175:203-209.

14. Mozaffari F, Hansson L, Kiaii S, Ju X, Rossmann ED, Rabbani H, Mellstedt H, Osterborg A: Signalling molecules and cytokine production in T cells of multiple myeloma-increased abnormalities with advancing stage. Br J Haematol 2004, 124:315-324.

15. Chen S, Zha X, Yang L, Li B, Liye Z, Li Y: Deficiency of CD3gamma, delta, epsilon, and zeta expression in T cells from AML patients. Hematology 2011, 16:31-36.

16. Chowdhury B, Tsokos CG, Krishnan S, Robertson J, Fisher CU, Warke RG, Warke VG, Nambiar MP, Tsokos GC: Decreased stability and translation of T cell receptor zeta mRNA with an alternatively spliced 3'-untranslated region contribute to zeta chain down-regulation in patients with systemic lupus erythematosus. J Biol Chem 2005, 280:18959-18966.

17. Jensen JP, Hou D, Ramsburg M, Taylor A, Dean M, Weissman AM: Organization of the human $T$ cell receptor zeta/eta gene and its genetic linkage to the Fc gamma RII-Fc gamma RIII gene cluster. J Immuno/ 1992, 148:2563-2571.

18. Pang M, Abe T, Fujihara T, Mori S, Tsuzaka K, Amano K, Koide J, Takeuchi T: Up-regulation of a $E$ 7, a novel integrin adhesion molecule, on $T$ cells from systemic lupus erythematosus patients with specific epithelial involvement. Arthritis Rheum 1998, 41:1456-1463.

19. Moulton VR, Tsokos GC: Alternative Splicing Factor/Splicing Factor 2 Regulates the Expression of the $\zeta$ Subunit of the Human T Cell Receptor-associated CD3 Complex. J Biol Chem 2010, 285:12490-12496.

20. Giunchi L, Nocentini G, Ronchetti S, Bartoli A, Riccardi C, Migliorati G: TCR kappa, a new splicing of the murine TCR zeta gene locus, is modulated by glucocorticoid treatment. Mol Cell Biochem 1999, 195:47-53.

21. Takeuchi T, Tsuzaka K, Pang M, Amano K, Koide J, Abe T: TCR zeta chain lacking exon 7 in two patients with systemic lupus erythematosus. Int Immunol 1998, 10:911-921.

22. Moser KL, Neas BR, Salmon JE, Yu H, Gray-McGuire C, Asundi N, Bruner GR, Fox J, Kelly J, Henshall S, et al: Genome scan of human systemic lupus erythematosus: evidence for linkage on chromosome 1q in African American pedigrees. Proc Natl Acad Sci USA 1998, 95:14869-14874.

23. Nambiar MP, Enyedy EJ, Warke VG, Krishnan S, Dennis G, Kammer GM, Tsokos GC: Polymorphisms/Mutations of TCR-乙-Chain Promoter and 3'Untranslated Region and Selective Expression of TCR $\zeta$-Chain with an Alternatively Spliced 3'Untranslated Region in Patients with Systemic Lupus Erythematosus. J Autoimmunol 2001, 16:133-142.

24. Johnson JM, Castle J, Garrett-Engele P, Kan Z, Loerch PM, Armour CD, Santos R, Schadt EE, Stoughton R, Shoemaker DD: Genome- wide survey of human alternative pre-mRNA splicing with exon junction microarrays. Science 2003, 302:2141-2144.

25. Black DL: Mechanisms of alternative pre-messenger RNA splicing. Annu Rev Biochem 2003, 72:291-336.

26. Cáceres JF, Stamm S, Helfman DM, Krainer AR: Regulation of alternative splicing in vivo by overexpression of antagonistic splicing factors. Science 1994, 265:1706-1709.

27. Krainer AR, Conway GC, Kozak D: Purification and characterization of premRNA splicing factor SF2 from HeLa cells. Genes Dev 1990, 4:1158-1171.

28. Li $X L$, Manley JL: New talents for an old acquaintance: the SR protein splicing factor ASF/SF2 functions in the maintenance of genome stability. Cell Cycle 2005, 4:1706-1708.

29. Ge H, Manley JL: A protein factor, ASF, controls cell-specific alternative splicing of SV40 early premRNA in vitro. Cell 1990, 62:25-34. 
30. Fu XD: The superfamily of arginine/serine-rich splicing factors. RNA 1995 , 1:663-680.

31. Sanford JR, Longman D, Caceres JF: Multiple roles of the SR protein family in splicing regulation. Prog Mol Subcell Biol 2003, 31:33-58.

32. Massiello A, Chalfant CE: SRp30a (ASF/SF2) regulates the alternative splicing of caspase-9 pre-mRNA and is required for ceramide-responsiveness. J Lipid Res 2006, 47:892-899.

33. Lemaire R, Winne A, Sarkissian M, Lafyatis R: SF2 and SRp55 regulation of CD45 exon 4 skipping during T cell activation. EUR J IMMUN 1999, 29:823-837.

34. Quentmeier H, Eberth S, Romani J, Zaborski M, Drexler HG: BCR-ABL1-independent P13Kinase activation causing imatinib-resistance. J Hematol Oncol 2011, 4:6.

35. Moulton VR, Kyttaris VC, Juang YT: The RNA-stabilizing Protein HuR Regulates the Expression of Chain of the Human T Cell Receptor-associated CD3 Complex. J Biol Chem 2008, 283:20037-20044.

36. Huang L, Chen S, Zha X, Yang L, Li B, Yu Z, Wang L, Li Y: Expression feature of CD3, FceRly and Zap-70 in patients with chronic lymphocytic leukemia. Hematology 2012, 17:71-75.

37. Zha X, Chen S, Yang L, Shi L, Li B, Wu X, Lu Y, Li Y: Up-regulated TCRC enhances interleukin-2 production in T-cells from patients with CML. DNA Cell Biol 2012, in press.

38. Shiue L, Zoller MJ, Brugge JS: Syk is activated by phosphotyrosinecontaining peptides representing the tyrosine-based activation motifs of the high affinity receptor for IgE. J Biol Chem 1995, 270:10498-10502.

39. Oliver JM, Burg D, Wilson BS, McLaughlin JL, Geahlen RL: Inhibition of mast cell Fc«Rl-mediated signaling and effector function by the Syk-selective inhibitor, piceatannol. J Biol Chem 1994, 269:29697-29703.

40. Taylor N, Jahn T, Smith S, Lamkin T, Uribe L, Liu Y: Differential activation of the tyrosine kinases ZAP-70 and Syk after FcgRl stimulation. Blood 1997, 89:388-396.

41. Wang H, Kadlecek TA, Au-Yeung BB, Goodfellow HE, Hsu LY, Freedman TS, Weiss A: ZAP-70: an essential Kinase in T-cell signaling. Cold Spring Harb Perspect Biol 2010, 2:a002279.

42. Baniyash M: TCR zeta-chain downregulation: curtailing an excessive inflammatory immune response. Nat Rev Immunol 2004, 4:675-687.

43. Whiteside TL: Signaling defects in T lymphocytes of patients with malignancy. Cancer Immunol Immun 1999, 48:346-352.

doi:10.1186/1756-8722-5-74

Cite this article as: Zha et al: Alternative expression of TCR related genes in patients with chronic myeloid leukemia. Journal of Hematology \& Oncology 2012 5:74.

\section{Submit your next manuscript to BioMed Central and take full advantage of:}

- Convenient online submission

- Thorough peer review

- No space constraints or color figure charges

- Immediate publication on acceptance

- Inclusion in PubMed, CAS, Scopus and Google Scholar

- Research which is freely available for redistribution 